\title{
DISCURSO COLETIVO EM UM GRUPO DE ESTUDOS E PESQUISA: CONSIDERAÇÕES SOBRE A PARTICIPAÇÃO E SUAS IMPLICAÇÕES
}

\section{COLLECTIVE DISCOURSE IN A RESEARCH AND STUDY GROUP: CONSIDERATIONS ABOUT PARTICIPATION AND ITS IMPLICATION}

Maria Cristina Lima Paniago, Katia Alexandra de Godoi e Silva

Universidade Católica Dom Bosco

E-mail: cristina@ucdb.br, katigodoi@gmail.com

\section{Resumo}

Este trabalho tem por objetivo analisar o discurso coletivo dos integrantes do Grupo de Estudos e Pesquisa em Tecnologia Educacional e Educação a Distância (GETED) sobre a sua participação e implicações. Para atingir tal objetivo utilizamos uma abordagem metodológica quantitativa e qualitativa. Para a análise qualitativa utilizamos a metodologia do Discurso do Sujeito Coletivo (DSC). A fundamentação teórica que pauta este estudo provém da tessitura dos conceitos de participação e participação periférica legítima. De modo geral, os resultados apontam para a falta de tempo desses integrantes em relação à participação no grupo, além de mostrar a importância de aprofundar e vislumbrar outros estudos sobre a participação desses integrantes do grupo de pesquisa e estudo.

Palavras-chave: grupo de pesquisa. discurso do sujeito coletivo. participação periférica legítima.

\section{Abstract}

This paper aims to analyze the collective discourse of the members of the Group of Studies and Research in Educational Technology and Distance Education (GETED) on their own participation and implications. In order to achieve this aims we use a quantitative and qualitative methodological approach. For the analysis of qualitative we used the Discourse of the Collective Subject (DSC) methodology. The theoretical framework that guides this study comes from the fabric of the concepts of participation and legitimate peripheral participation. In general, the results showed the lack of time these members for the participation in the group, in addition to show the importance of deepening and envision other studies on the participation of those members of the research group and study.

Palavras-chave: research group. discourse of the collective subject. legitimate peripheral participation. 


\section{INTRODUÇÃO}

O objetivo deste estudo é analisar o discurso coletivo dos integrantes de um Grupo de Pesquisa, tanto no que se refere a uma avaliação geral sobre o conteúdo abordado, o pesquisador participante do grupo, bem como a própria participação no grupo.

A partir deste objetivo surge a seguinte indagação: Como se desenvolve a participação em um grupo de pesquisa e o que ela implica?

Para responder essa questão utilizamos uma abordagem metodológica quantitativa e qualitativa (GATTI, 2004, 2012), esta última com base no Discurso do Sujeito Coletivo (DSC) (LEFEVRE; LEFREVE, 2005, 2012, 2014). Neste estudo, essas abordagens são utilizadas como complementares, ou seja, as duas abordagens permitem análises nos seus diferentes aspectos, a pesquisa quantitativa pode gerar questões para serem aprofundadas qualitativamente, e vice-versa.

Além desta introdução, este trabalho conta com cinco partes, sendo a primeira um histórico sobre o Grupo de Pesquisa e Estudos em Tecnologia Educacional e Educação a Distância (GETED). A segunda a metodologia da pesquisa. A terceira apresenta os resultados e a quarta a análise desses resultados, os quais foram analisados a luz dos referenciais teóricos que podem subsidiar as questões do processo de participação (FREIRE, 1991, 2003; LAVE; WEGER, 1991; PANIAGO, 2007) dos integrantes do grupo. A última parte trata da conclusão do estudo apresentado. 


\section{O GETED}

O Conselho Nacional de Desenvolvimento Científico e Tecnológico (CNPq) cadastra os Grupos de Pesquisa no Brasil. Para tanto, mantém um Diretório de Grupos de Pesquisa com o registro das informações, as quais estão disponíveis para consulta, além de atribuir um selo de certificação.

De acordo com a súmula estatística por área do ano de 2010, o CNPq conta com 27.523 Grupos de Pesquisa. A área de Educação possui 2.236 grupos, os quais representam 8,1\% dos grupos de todas as áreas do conhecimento.

O recorte deste trabalho reside em um estudo inicial sobre o discurso coletivo dos integrantes do Grupo de Pesquisa e Estudos em Tecnologia Educacional e Educação a Distância (GETED).

Este grupo, certificado pelo CNPq, foi criado em 2006, pelas pesquisadoras Profa. Dra. Maria Cristina Lima Paniano e Profa. Dra. Arlinda Cantero Dorsa.

Tem por objetivo promover espaços para discussão, formação, compartilhamento, trocas, problematização e desenvolvimento de práticas, trabalhos, pesquisas, materiais, concepções, experiências e redes relacionadas à inserção das Tecnologias de Informação e Comunicação (TIC) no contexto educacional, tanto presencial como a distância e à formação e prática docente. Assim como, fornecer subsídios teóricos e práticos às pessoas interessadas nas temáticas da tecnologia educacional como da educação a distância, no sentido de promover letramento, formação, alfabetização tecnológica crítica, reflexiva, pró-ativa, participativa e colaborativa.

O GETED reúne atualmente 12 pesquisadores (Universidade Católica Dom Bosco - UCDB; Universidade Estadual de Mato Grosso do Sul - UEMS; Universidade Federal de Mato Grosso 
do Sul - UFMS e Centro de Estudos das Migrações e das Relações Interculturais - CEMRI, da Universidade Aberta) e oito estudantes (Graduação, Mestrado e Doutorado) da UCDB e outras instituições cadastrados no CNPq. Além de professores da rede estadual e municipal de Educação do Estado de Mato Grosso do Sul. Todos com um interesse comum em pesquisar e estudar as TIC e suas relações na prática docente e a Educação a Distância.

Esses pesquisadores e estudantes reunem-se em encontros presenciais, os quais acontecem a cada 15 dias, e a distância, por meio de palestras utilizando as ferramentas Hangout e Ning. Além de manterem um grupo fechado na rede social Facebook.

No intuito de analisar o discurso coletivo dos integrantes do GETED sobre a avaliação geral do conteúdo abordado, os pesquisadores participantes e a própria participação no grupo, optamos por uma abordagem metodológica quantitativa e qualitativa, a qual será explicada no tópico a seguir. 


\section{METODOLOGIA}

Como anunciado anteriormente, este estudo traz duas abordagens de análise de dados: a quantitativa e a qualitativa. As quais se complementam, pois se caracterizam como um esforço e ampliação do conhecimento sobre o discurso dos integrantes do GETED.

Corroborando Gatti (2004, p. 13):

Os métodos de análise de dados que se traduzem por números podem ser muito úteis na compreensão de diversos problemas educacionais. Mais ainda, a combinação deste tipo de dados com dados oriundos de metodologias qualitativas, podem vir a enriquecer a compreensão de eventos, fatos, processos. As duas abordagens demandam, no entanto, o esforço de reflexão do pesquisador para dar sentido ao material levantado e analisado.

Gatti (2012, p. 1) explica ainda que: "Nas pesquisas científicas partimos sempre de um problema cujo enunciado já diz da perspectiva em que nos situamos teórica e epistemologicamente". No caso deste estudo, nosso problema é comprender como se desenvolve a participação em um grupo de pesquisa. Para a mesma autora:

Ao enunciá-lo ele traduz nosso modo de ver a questão a examinar; ou seja, a enunciação do problema a investigar já mostra o olhar teórico sobre a temática em exame e é esse olhar que vai dirigir nossa investigação e as formas de aproximação do levantamento e da análise dos dados obtidos. Assim, não é o uso de dados quantitativos ou qualitativos que diferencia formas de abordagem de questões em investigação, mas, sim, a perspectiva que nos guia nessa investigação. (GATTI, 2012, p. 1)

Para o recorte de estudo, trabalhamos com os dados quantitativos e qualitativos numa perspectiva dialética. Desta forma, realizamos o levantamento de dados em dois momentos 
distintos: junho de 2014 e dezembro de 2014, utilizando dois instrumentos.

O instrumento de coleta de dados utilizado foi o questionário. Para Gil (1994), o questionário é a forma mais usada para coletar dados. É uma relação de perguntas que o entrevistado responde sozinho, assinalando ou escrevendo as respostas.

Assim, ao final do primeiro semestre de 2014, solicitamos aos integrantes do GETED responderem um questionário on-line utilizando a ferramenta Google Docs, que continha questões quantitativas, relacionadas ao conteúdo abordado nas reuniões, assim como, relacionadas aos pesquisadores do grupo. Nesse mesmo questionário também havia questões de cunho qualitativo, nas quais os integrantes do grupo completavam os espaços para enriquecer sua opinião com comentários e sugestões (p. ex.: Eu poderia ter aproveitado mais se..., Tive uma certa resistência em..., Foi muito bom..., Não gostei..., Gostei muito..., Faltou..., Sugiro...).

Ao final do segundo semestre também pedimos aos integrantes do GETED que respondessem um questionário, mas desta vez impresso, o qual contou com três partes: a quantitativa, que tratou de questões relacionadas ao conteúdo abordado nas palestras, sobre os pesquisadores e os palestrantes e também sobre a participação individual dos integrantes e do grupo; a qualitativa, com espaços para que os integrantes pudessem enriquecer sua opinião com comentários e sugestões (p. ex.: Eu poderia ter aproveitado mais se...; Foi muito bom...; Não gostei...; Faltou...); a parte de sugestões, com propostas de temas para palestras no ano de 2015.

Antes de prosseguir com as explicações sobre o recorte da análise dos questionários, vale destacar e justificar a quantidade de integrantes que responderam aos questionários. Por tratar-se de um estudo quantitativo e qualitativo consideramos significativo a amostragem dos respondentes, pois as duas abordagens contribuíram para a interpretação dos dados apresentados, tanto no primeiro, quanto no segundo questionário. 
A amostragem que trabalhamos neste estudo é a denominada 'amostragem por acessibilidade', ou seja, selecionamos os elementos a que tivemos acesso. Segundo Silva (2005), é um tipo de amostragem não-probabilística, pois ela não possui relação com a estatística, por isso é menos rigorosa e pode ser utilizada em estudos qualitativos.

Assim, no primeiro questionário, num universo de 20 integrantes do GETED, contamos com uma amostragem de cinco respondentes. Acreditamos que este número deve-se ao fato de que, nem todos os integrantes do grupo tiveram tempo para responder ao questionário online.

Já no segundo questionário, tivemos uma amostragem de dez respondentes. Este número justifica-se pelo fato de que, nem todos os integrantes do grupo estavam presentes no último encontro presencial.

Nosso pressuposto é que a ausência dos integrantes respondentes pode estar relacionada à falta de tempo e a participação efetiva no grupo.

No intuito de trazer uma análise dos dois questionários, fizemos um recorte e optamos por fazer o tratamento das seguintes questões: Quantitativa (em relação ao conteúdo abordado, ao pesquisador e a participação); Qualitativa (Eu poderia ter aproveitado mais se..., Foi muito bom..., Não gostei..., Faltou..., Sugestões...).

Para a análise das questões quantitativas optamos por usar gráficos para ilustrar a opinião dos integrantes. Já na análise das questões qualitativas optamos por trazer as opiniões dos integrantes em um discurso único e coletivo.

Mas como fazer com que, empiricamente, um conjunto de questões abertas possa gerar opiniões coletivas? 
Para responder tal indagação, utilizamos o método do Discurso do Sujeito Coletivo (DSC). Segundo Lefevre e Lefevre (2014), o DSC é uma forma de metodologicamente resgatar e apresentar as Representações Sociais (RS) obtidas de pesquisas empíricas.

Lefevre e Lefevre $(2005,2012,2014)$ explicam também que, o DSC resgata o pensamento de uma coletividade elaborando um discurso sobre um determinado tema. Esse resgate do pensamento de uma coletividade sobre determinado objeto de estudo, realizado por meio de pesquisa social empírica, só é legitimado pelo depoimento discursivo. Este depoimento é composto por uma ideia central e seus conteúdos e argumentos. No DSC é através do discurso de vários indivíduos e a livre expressão de seus depoimentos mediante perguntas abertas, que se chega ao discurso coletivo. Entretanto, para isso, é preciso acreditar que é possível produzir uma soma de vários discursos.

Nessa perspectiva, para elaborar o pensamento coletivo, é necessário somar qualitativamente pensamentos individuais iguais, agregando elementos que compõem 'respostas semelhantes de indivíduos distintos', transformando as respostas em um discurso coletivo com sentido.

O processo de elaboração de um discurso coletivo com sentido é complexo e, de acordo com Lefevre e Lefevre (2012), são necessárias operações ou figuras metodológicas:

- Expressões-Chave (ECH) - trechos escolhidos de cada depoimento, que melhor descrevem o conteúdo do depoimento;

- Ideias Centrais (IC) - ideias que descrevem de maneira sintética e precisa o sentido das EHC de cada um dos discursos analisados. A IC recebe também o nome de Categoria.

- Discurso do Sujeito Coletivo (DSC) - reunião num só discurso-síntese, elaborado na primeira pessoa do singular, das ECH que tem a mesma IC. 
Lefevre e Lefevre (2014, p. 504) esclarecem ainda que:

[...] longe de serem meras empirias, os DSC são abstrações concretizadas na medida em que a sua construção se dá num movimento dialético em que os conteúdos e argumentos das opiniões individuais de sentido semelhante são "minerados" (no sentido de mineração) nos depoimentos individuais e abstraídos na categoria que os unifica, permanecendo contudo, a despeito da abstração, como conteúdos e argumentos do DSC.

Os autores enfatizam também que, os DSC são opiniões individuais que, ao passarem pela análise do pesquisador, o que exige o uso das operações de abstração e conceituação, são transformadas em discursos científicos, os quais mantêm as características espontâneas e reconhecíveis da fala cotidiana.

O resultado final de uma pesquisa como a utilização dessa metodologia é uma tentativa de descrição da realidade e uma reconstrução do pensamento coletivo como construção científica.

Para a criação do DSC, neste estudo, foram inicialmente escolhidas as ECH das respostas relacionadas aos dois questionários; em seguida, foram selecionadas as IC de cada ECH; e por fim, a construção das IC. Criadas as IC, foram elaborados os DSC para cada IC, transformando as respostas em um discurso coletivo.

Optamos trazer como IC, as partes qualitativas das frases introdutórias do próprio questionário: Eu poderia ter aproveitado mais se..., Foi muito bom..., Não gostei..., Faltou..., Sugestões...

Assim, no texto, será possível identificar as operações 2 e 3 (IC e DSC). Como mostram os resultados a seguir. 


\section{RESULTADOS}

A análise dos dados refere-se aos dois questionários aplicados no final do 1 ㅇ e 20 semestres de 2014. Assim, este tópico está organizado em: análise do questionário do 10 semestre e análise do questionário do 2 을 semestre.

\subsection{Análise do questionário do 10 semestre}

O questionário do 1ㅇ semestre estava organizado em duas partes: a quantitiva e a qualitativa.

Na parte quantitativa, o questionário abordou três aspectos, os quais trataram do conteúdo, dos pesquisadores e de outros aspectos gerais sobre o grupo.

Em relação ao conteúdo, o questionário abarcou questões sobre: o tempo para leitura dos textos sugeridos, da avaliação geral dos temas, as discussões ocorridas nas reuniões, a contribuição para o desenvolvimento de pesquisas em Tecnologia na Educação e Educação a Distância, as contribuição ao projeto de pesquisa do integrante do grupo, os objetivos atingidos, a exposição dos objetivos, a bibliografia fornecida e a abordagem dos temas discutidos.

Tabela 1. Sobre o conteúdo abordado.

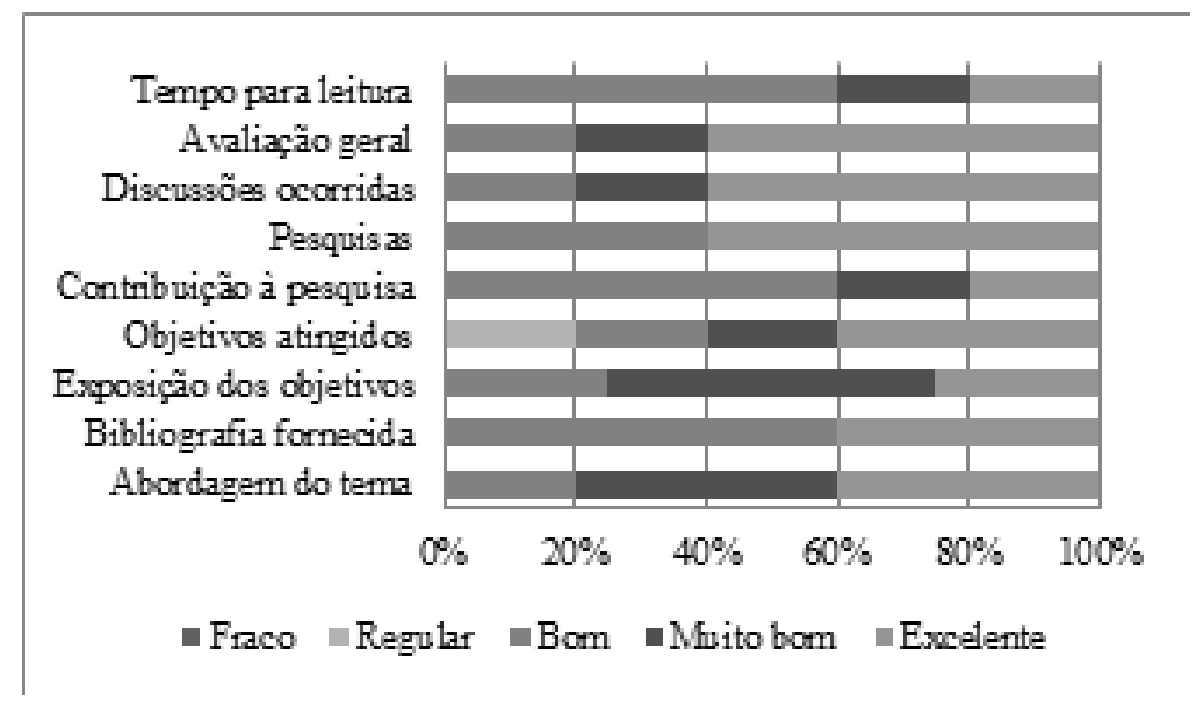


Fonte: Autoras.

A partir da análise da tabela 1, é possível verificar de modo geral que, em relação ao tempo para leitura dos textos discutidos, $60 \%$ dos integrantes do grupo consideraram como - Bom, $20 \%$ como - Muito bom e 20\% como - Excelente. Em uma avaliação geral, $20 \%$ dos integrantes consideraram o conteúdo, como - Bom, 20\% como - Muito bom e 60\% como Excelente.

Sobre as discussões ocorridas sobre o conteúdo trabalhado, $20 \%$ colocam como - Bom, $20 \%$ como - Muito bom e 60\% como - Excelente.

Em relação à contribuição das pesquisas em TIC e EaD, $40 \%$ dos integrantes consideram como - Bom e $60 \%$ como - Excelente. Para a contribuição à pesquisa de cada integrante do grupo, $60 \%$ colocaram como - Bom, $20 \%$ como - Muito bom e $60 \%$ como - Excelente.

Sobre a exposição dos objetivos, $25 \%$ afirmam como - Bom, $50 \%$ como - Muito bom, $25 \%$ como - Excelente. E, se objetivos foram atingidos, $20 \%$ dos integrantes, ponderaram como Regular, $20 \%$ como - Bom, 20\% como - Muito bom e 40\% como - Excelente.

Sobre a bibliografia fornecida, $60 \%$ aceitam como - Bom e $40 \%$ como - Excelente. E, por fim, a abordagem do tema, $20 \%$ consideram como - Bom, $40 \%$ como - Muito bom e $40 \%$ como Excelente.

Em relação aos pesquisadores, o questionário abordou as seguintes temáticas: o desempenho dos pesquisadores de uma maneira geral; o incentivo à participação dos integrantes do grupo; a coerência no desenvolvimento do conteúdo; a forma de exposição das ideias. 
Tabela 2. Sobre os pesquisadores.

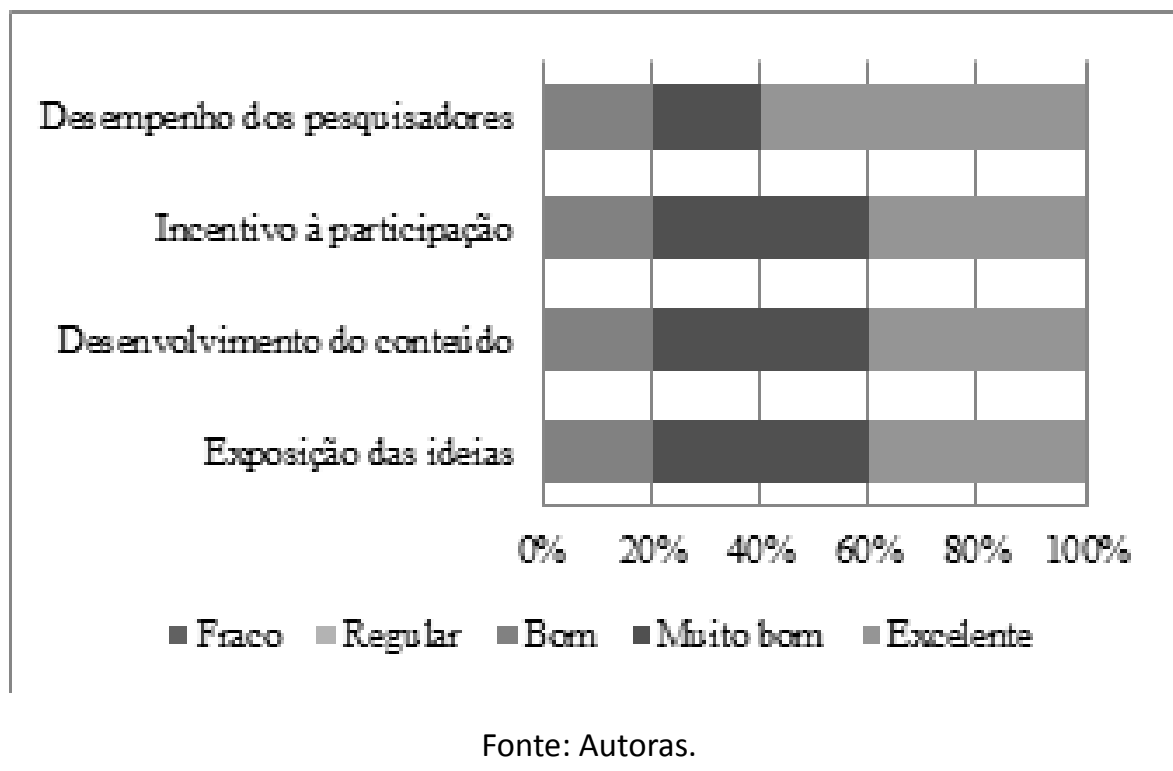

Os dados da tabela 2 revelam que, sobre o desempenho dos pesquisadores, $20 \%$ dos integrantes do grupo consideram como - Bom, $20 \%$ como - Muito bom e $40 \%$ como Excelente.

Em relação ao incentivo à participação, os integrantes responderam que $20 \%$ consideram como - Bom, $40 \%$ como - Muito bom e $40 \%$ como - Excelente.

Sobre o desenvolvimento do conteúdo, $20 \%$ dos participantes acreditam que seja - Bom, $40 \%$ como - Muito bom e $40 \%$ como - Excelente. E sobre a exposição das ideias, os integrantes concordam que $20 \%$ seja - Bom, $40 \%$ como - Muito bom e $40 \%$ como Excelente.

Em relação à participação, o questionário abordou: a participação dos membros do grupo presentes na reunião; o tempo de horas em relação ao conteúdo; a própria contribuição do integrante.

Tabela 3. Sobre a participação. 


\section{A participaçäo dos membros do grupo presentes na reuniäo foi \\ O tempo de horas em relaçâo ao conteudo}

Eu contribui de que maneira

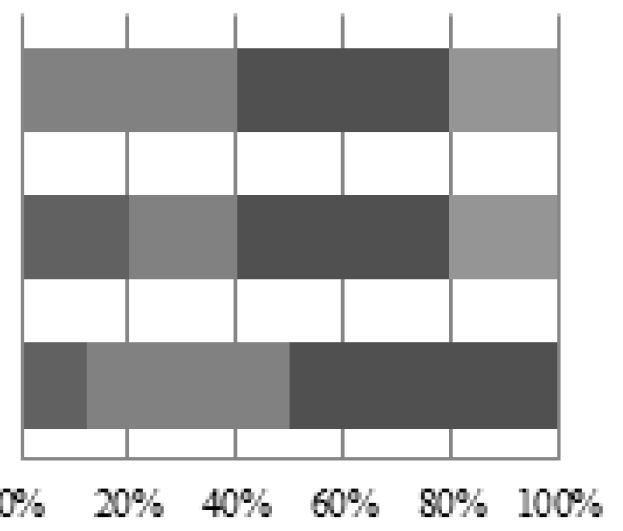

- Fraco $\quad$ Regular Bom $n$ Mritobom Ewcelente

Fonte: Autoras.

A tabela 3 apresenta os outros aspectos tratados no questionário sobre: a participação dos membros do grupo presentes nas reuniões, o tempo de horas em relação conteúdo e sobre a própria contribuição dos integrantes do grupo.

A participação dos membros do grupo presentes na reunião, $40 \%$ dos integrantes responderam como - Bom, 40\% como - Muito bom e 20\% como - Excelente.

O tempo de horas em relação ao conteúdo, $20 \%$ dos integantes consideram como - Fraco, $20 \%$ como Bom, $40 \%$ como - Muito bom e $20 \%$ como - Excelente.

Sobre a própria contribuição, $10 \%$ considerou - Fraco, $40 \%$ como - Bom e $50 \%$ como Excelente.

Na parte qualitativa, como explicamos na metodologia, utilizamos como IC, o início das questões qualitativas do quetionário (Eu poderia ter aproveitado mais se..., Foi muito bom..., Não gostei..., Faltou..., Sugestões...) e o DSC construímos, na primeira pessoa do singular, as opiniões dos integrantes do grupo, apresentadas a seguir. 
Eu poderia ter aproveitado mais se... Aproveitei bem! Mas poderia ter aproveitado mais se tivesse participado de todos os encontros. E também, se tivesse um tempinho a mais para me dedicar e trocar experiências.

Foi muito bom... Participar dos encontros, pelo aprendizado e a troca de conhecimentos.

Não gostei... De não ter tido oportunidade de participar mais efetivamente.

Faltou... Não faltou nada. Mas sinto falta de mais comunicação, por meio de e-mail e Whatsapp, pois às vezes acabo me esquecendo de olhar no grupo do Facebook.

Sugestões... Mais momentos para estudos com o grupo, como por exemplo, leituras e referencias sobre mobilidade e pensar em novas estratégias de comunicação e informação.

\subsection{Análise do questionário do $2 \cong$ semestre}

Da mesma forma que o questionários do 10 semestre, o questionário do 2 o semestre estava organizado em duas partes: a quantitiva e a qualitativa.

Na parte quantitativa, o questionário abordou três aspectos, os quais trataram do conteúdo, do pesquisador e de outros aspectos gerais sobre o grupo.

Em relação ao conteúdo, o questionário abarcou questões relacionadas ao tempo para leitura dos textos sugeridos, à avaliação geral dos temas, às discussões ocorridas nas reuniões, à contribuição para o desenvolvimento de pesquisas em Tecnologia na Educação e Educação a Distância, à contribuição ao projeto de pesquisa do integrante do grupo, aos objetivos atingidos, à exposição dos objetivos, a bibliografia fornecida e à abordagem dos temas. 
Tabela 4. Sobre o conteúdo abordado.

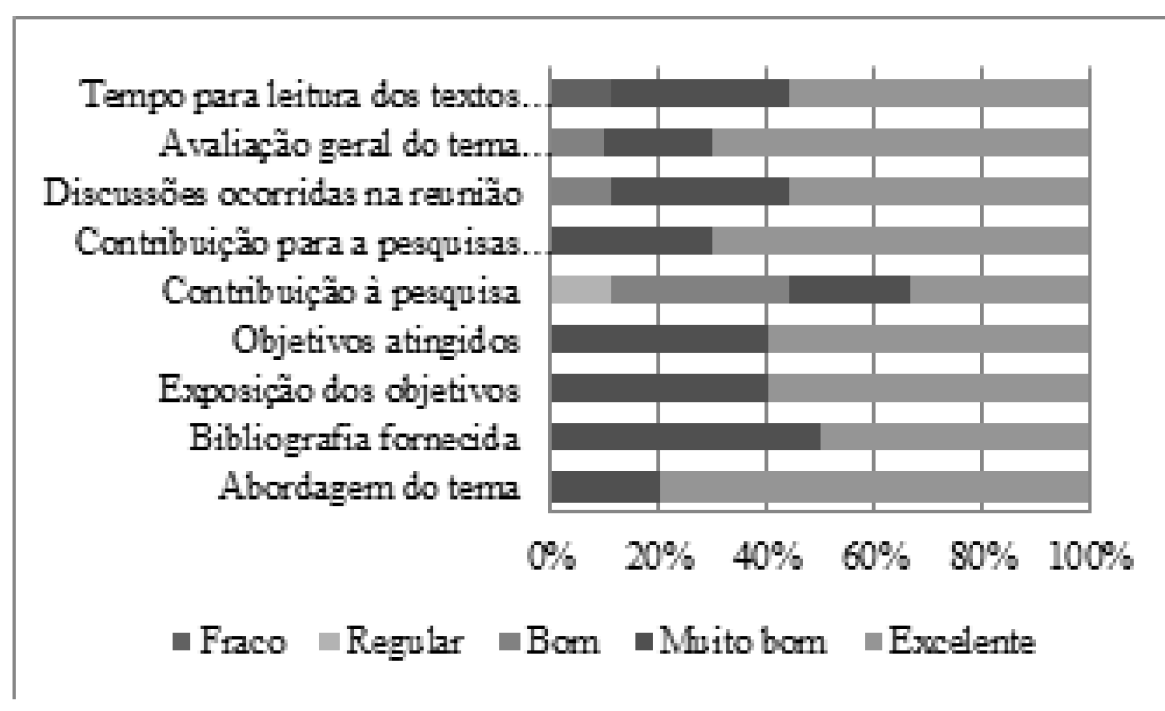

Fonte: Autoras.

A tabela 4 revela sobre o tempo para leitura dos textos, $10 \%$ dos integrantes consideraram como - Fraco, $40 \%$ como - Muito bom e 50\% como - Excelente.

Sobre a avaliação geral dos temas, $10 \%$ dos integrantes consideraram como - Bom, $20 \%$ como - Muito bom e 70\% como - Excelente.

Em relação às discussões ocorridas nas reuniões, $10 \%$ dos integrantes ponderaram como Bom, $40 \%$ como - Muito bom e $50 \%$ como - Excelente.

A contribuição à pesquisa na área das TIC e da EaD, 30\% dos integrantes responderam como - Muito bom e 70\% como - Excelente. E, a contribuição à pesquisa para cada um, 10\% dos integrantes colocam como - Regular, 30\% como - Bom, $20 \%$ como - Muito bom e $40 \%$ como - Excelente.

Os objetivos das palestras, $40 \%$ dos integrantes consideraram - Muito bom e $60 \%$ Excelente. Se esses objetivos foram atingidos, da mesma forma, $40 \%$ dos integrantes consideraram - Muito bom e 60\% - Excelente. 
Sobre a bibliografia fornecida, $50 \%$ dos integrantes ponderaram - Muito bom e $50 \%$ Excelente. E sobre os temas abordados nas palestras, $20 \%$ dos integrantes consideraram Muito bom e $80 \%$ - Excelente.

Em relação aos palestrantes, o questionário abarcou questões relacionadas ao desenvolvimento, incentivo, coerência e exposição das ideias.

Tabela 5. Sobre os palestrantes.

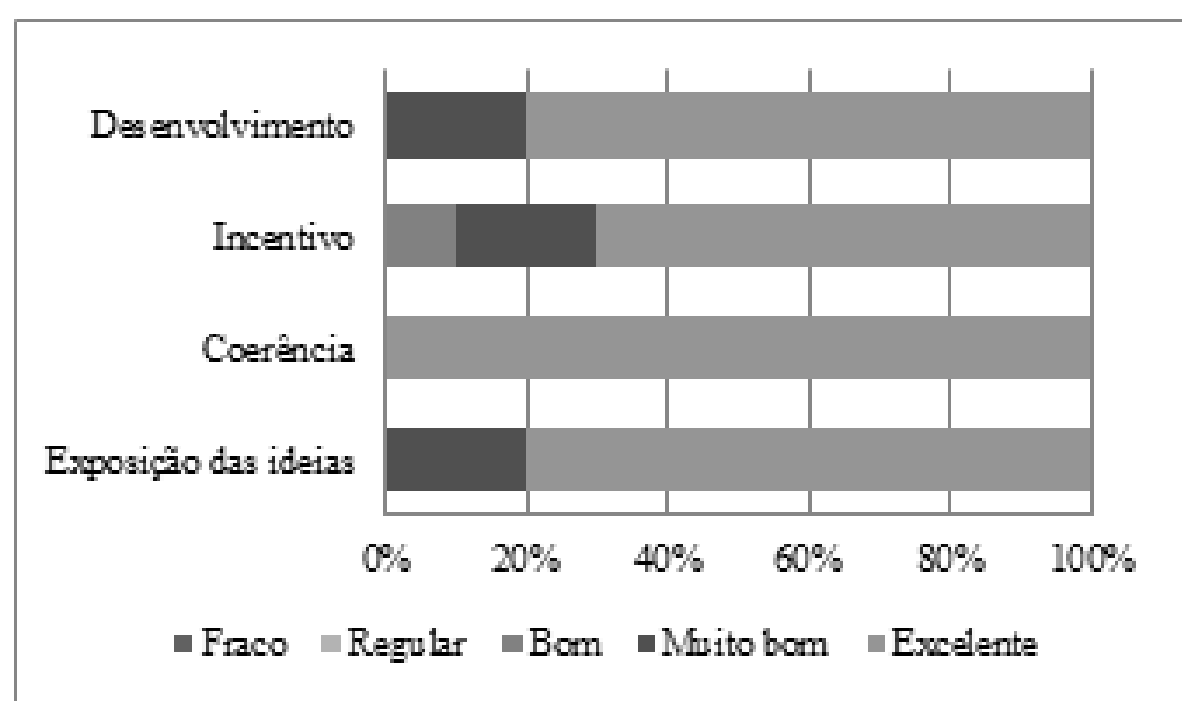

Fonte: Autoras.

A tabela 5 demonstra que em relação ao desenvolvimento dos palestrantes, $20 \%$ dos integrantes do grupo considerou como - Muito bom e 80\% como - Excelente.

Em relação ao incentivo, 10\% dos integrantes responderam como - Bom, 20\% como - Muito bom e $70 \%$ como - Excelente.

Sobre a coerência, $100 \%$ dos integrantes consideraram como - Excelente.

Em relação à própria participação dos integrantes e a participação do grupo, o questionário trouxe os seguintes aspectos: participação dos membros do grupo nas reuniões; tempo de 
horas em relação ao conteúdo; você contribuiu de que maneira.

Tabela 6. Sobre a participação.

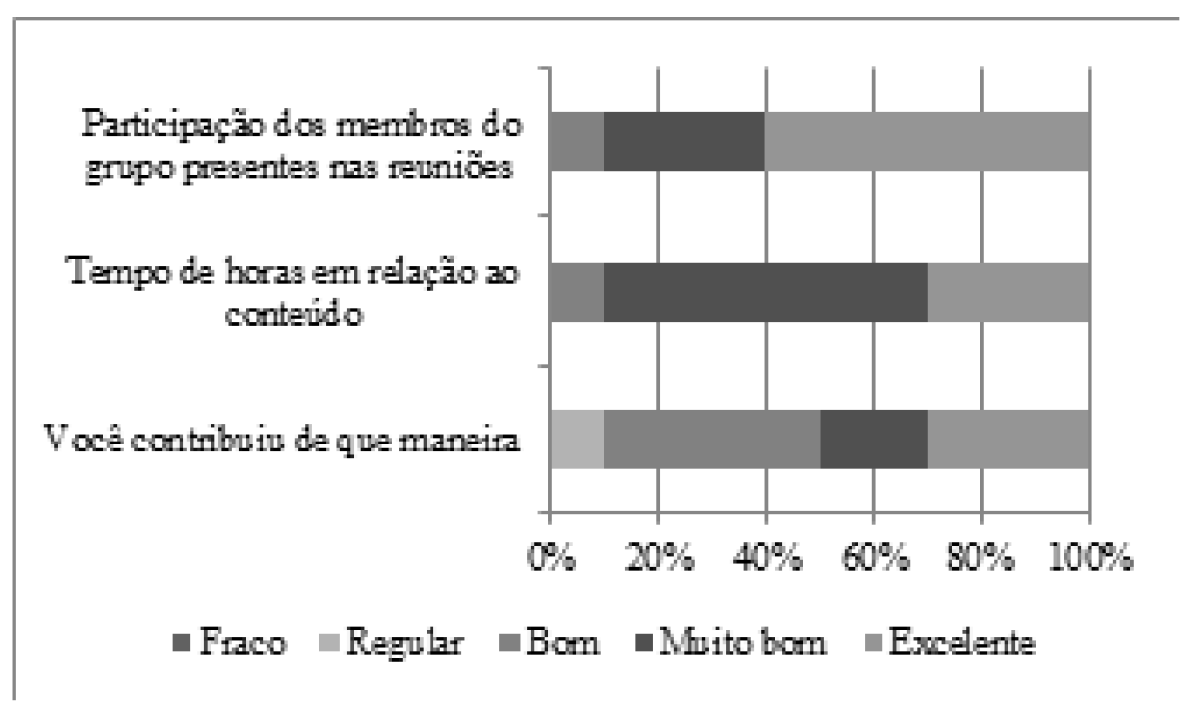

Fonte: Autoras.

O gráfico da Tabela VI revela que em relação à participação dos membros do grupo presentes nas reuniões, $10 \%$ dos integrantes consideram como - Bom, $30 \%$ como - Muito bom e $60 \%$ como - Excelente.

O tempo de horas em relação ao conteúdo, 10\% dos integrantes avaliaram como - Bom, 70\% como - Muito bom e $20 \%$ como - Excelente.

Sobre a própria contribuição, $10 \%$ dos integrantes consideram como - Regular, 50\% como Boa, $20 \%$ como - Muito boa e $30 \%$ como - Excelente.

Na parte qualitativa, como explicamos na metodologia, utilizamos como IC, o início das questões qualitativas do questionário (Eu poderia ter aproveitado mais se..., Foi muito bom..., Não gostei..., Faltou..., Sugestões...) e o DSC construímos, na primeira pessoa do singular, as opiniões dos integrantes do grupo, apresentadas a seguir.

Eu poderia ter aproveitado mais se... Nos momentos em que estive nas 
reuniões aproveitei bastante! Mas eu poderia ter aproveitado mais se tivesse acesso anterior aos textos propostos, pois poderia interagir melhor e expor mais minhas opiniões. Acho também que teria aproveitado mais se tivesse intercalado palestras e estudos de textos científicos no decorrer dos encontros.

Foi muito bom... A participação, as trocas e as reflexões nos encontros. Dialogar, discutir e conhecer outros palestrantes que trouxeram diferentes perspectivas e temáticas relacionadas às tecnologias.

Não gostei... De não ter me envolvido tanto este semestre.

Faltou... Uma parte prática com oficinas que inter-relacionem as tecnologias. Além de aprofundar os estudos, ou seja, após uma apresentação/palestra, ter mais um dia para debate e reflexão sobre a temática.

Por fim, os integrantes do GETED fizeram algumas sugestões de temáticas que gostariam para o ano de 2015. Essas temáticas estão relacionadas à Identidade docente na EaD, às Comunidades de práticas, às Tecnologias digitais e a autoria de alunos, à construção de Narrativas, às Relações entre linguagem e tecnologia digital, à Análise qualitativa e às Tecnologias interativas. 


\section{ANÁLISE DOS RESULTADOS}

A partir da análise dos resultados dos dois questionários é possível observar, de modo geral, que na maior parte dos aspectos tratados (conteúdo abordado; pesquisadores e palestrantes; participação), os integrantes do grupo consideraram como - Bom, Muito bom e/ou Excelente.

Além dessa análise geral, observamos que há um ponto convergente entre os dois questionários: a questão da participação dos integrantes do GETED.

Os dados quantitativos mostraram que esta participação está relacionada ao tempo para leitura dos textos/conteúdos abordados e sobre a própria contribuição no grupo.

O DSC confirmou essa convergência, ao revelar que os participantes poderiam ter aproveitado mais se tivessem participado de todos os encontros, se tivessem tido um tempo a mais e se tivessem um envolvimento maior.

A palavra participar, de acordo com o dicionário etimológico (CUNHA, 2010), significa 'fazer parte de, tomar parte em', 'fazer saber, informar, anunciar'.

Bordenave (1993) explica que é possível 'fazer parte sem tomar parte'. Esta é a diferença entre a participação passiva e a ativa.

A partir dessa análise podemos pensar que alguns integrantes do GETED fazem parte deste grupo. No entanto, ainda não tomaram parte, pois acreditam que precisam de mais tempo para participar dos encontros e fazer as leituras solicitadas, para poder colaborar com o grupo.

Para Freire (1991), a participação não garante e não pode ser reduzida a uma pura 
colaboração. Implica, um 'estar presente' e não simplesmente nele 'estar representado'. Implica também nas opções, nas decisões e não só de fazer o já programado.

Desta forma, Freire (2003) considera: "A participação enquanto exercício de voz, de ter voz, de interagir, de decidir [...]".

Lave e Weger (1991) trazem outros conceitos, a partir de outra perspectiva, intitulados 'participação periférica legítima' e 'comunidade de prática'. Esses conceitos estão vinculados a teoria da aprendizagem situada. Para o recorte deste artigo, nossas análises estão relacionadas ao primeiro conceito.

Diante disto, o processo de participação se legitimiza a partir do momento em que um membro do grupo se movimenta da periferia para o seu centro, tornando-se mais envolvido, adotando os instrumentos e práticas do grupo e assumindo uma participação mais integral, que gradualmente aumenta em complexidade e engajamento. Como pode ser visto, as noções de periferia e centro sugerem também mudanças de posição.

Na verdade, o termo 'periférica' não remete ao sentido negativo da palavra, mas sim ao fato de que existem diferentes maneiras de se engajar e que, até que se torne um participante pleno, o membro do grupo (p. ex. do GETED), pode ser considerado um participante periférico (LAVE; WENGER, 1991). Vale explicar ainda que, conforme destacam os autores, "a participação periférica legítima não é uma forma educacional, muito menos uma estratégia pedagógica ou uma técnica de ensino. É uma visão analítica da aprendizagem, uma maneira de entender a aprendizagem" (LAVE; WENGER, 1991, p. 40).

Assim, é possível considerar, de acordo com Lave e Weger (1991), que o GETED passa por processos de transformação constantes, os quais estão ancoradas nas formas de ação e participação dos membros no grupo. 
A partir dessa perspectiva, também podemos compreender que, apesar dos integrantes ainda não tomaram parte do grupo, ainda pode haver um processo de participação periférica legítima no GETED.

Pois a participação periférica não significa uma participação passiva em comparação com a participação ativa. Participação periférica legítima sugere uma abertura, um processo de envolvimento crescente de tornar-se parte do grupo.

Corroborando Lopes (2007), mesmo as participações podendo ser diferentes, a participação periférica legítima também tem o seu valor e pode convidar à reflexão, pois busca a aprendizagem, o crescimento, o desenvolvimento e o senso de envolvimento.

\section{CONCLUSÕES}

O presente estudo teve por objetivo analisar o discurso coletivo dos integrantes do GETED, tanto no que se refere a uma avaliação geral sobre o conteúdo abordado, o pesquisador participante do grupo, bem como a própria participação no grupo. Para tanto foi desenvolvido um estudo a partir de uma abordagem metodológica quantitativa e qualitativa, esta última com base no DSC.

Cabe observar que ficou claro que a metodologia com abordagem quantitativa e qualitativa pode trazer contribuições para a análise dos dados. DSC, por sua vez, mostrou-se capaz de dar conta do questionamento feito aos membros do GETED, pois a partir de uma proposta de pesquisa abrangente, viabilizou a pesquisa sobre a temática proposta, além de privilegiar a transparência nos procedimentos adotados e sem restrição de tamanho de amostra.

Terminamos este estudo ciente que trouxemos contribuições para iniciar a reflexão sobre o GETED. Acreditamos que conseguimos oferecer um panorama das questões que precisamos avançar no grupo: disponibilizar mais tempo para leituras e estudos, assim como propiciar 
que os integrantes tomem parte deste grupo.

Observamos, ainda, que toda pesquisa tem suas limitações, sejam teóricas, metodológicas ou referentes à pesquisa empírica. Por isso, não pretendemos esgotar todas as possibilidades de análise, pelo contrário, entendemos e aceitamos que mais estudos, não só empíricos como também teóricos, sejam feitos de forma a compreender melhor as peculiaridades da temática.

Portanto, ao completar este artigo, estamos conscientes de que precisamos aprofundar e vislumbrar outros estudos sobre a participação dos integrantes do GETED: utilizar outros instrumentos de coleta de dados, como por exemplo, a entrevista; explorar outros conceitos que emerjam do discurso dos integrantes do grupo; estudar e avançar nas reflexões sobre a teoria da aprendizagem situada e os dois conceitos que envolvem essa teoria: a participação periférica legítima e a comunidade de prática, principalmente nas redes sociais Facebook e Ning.

\section{AGRADECIMENTOS}

Agradeço ao Programa Nacional de Pós-Doutorado (PNPD/Capes) pelo financiamento deste estudo. 


\section{REFERÊNCIAS}

BORDENAVE, J. D. Bordenave. O que é participação? São Paulo: Editora Brasiliense, 1983.

CUNHA, A. G. Dicionário etimológico da Língua Portuguesa. Rio de Janeiro: Lexikon Editora, 2010.

FREIRE, P. A educação na cidade. São Paulo: Editora Cortez, 1991.

Pedagogia do Oprimido. Rio de Janeiro: Edições Paz e Terra, 2003.

GATTI, B. Estudos quantitativos em educação. Educação e Pesquisa, São Paulo, v.30, n.1, pp. 11-30, jan./abr. 2004.

Abordagens quantitativas e a pesquisa educacional. In: SEMINÁRIO DO INSTITUTO DE MATERMÁTICA E ESTATíSTICA DA USP, 2012, São Paulo. Anais eletrônicos... São Paulo: Universidade de São Paulo, 2012. Disponível em: <http://www.ime.usp.br/ marcos/Bernadete25052012.pdf> Acesso em: 30 set. 2015.

GIL, A. C. Métodos e técnicas de pesquisa social. São Paulo: Atlas, 1994.

LAVE, J.; WEGER, E. Situated learning: legitimate peripheral participation. New York: Cambridge University, 1991.

LEFEVRE, F.; LEFEVRE, A. M. C. Depoimentos e discursos. Uma proposta de análise em pesquisa social. São Paulo, Liberlivro, 2005.

Pesquisa de representação social: um enfoque qualiquantitativo. Brasília: Liber Livro Editora, 2012.

Discurso do sujeito coletivo: representações sociais e intervenções comunicativas. Texto Contexto, Florianópolis, v. 23, n.2, pp. 502-507, abr./jun. 2014.

LOPES, M. C. L. P. Relações entre professores, alunos, computador e sociedade em ambiente digital. Revista Lusófona de Educação, n. 9, pp.159-171. 2007.

SILVA, M. A. F. Métodos e técnicas de pesquisa. Curitiba: Ibpex, 2005. 